\title{
Mortalities induced by the copepod Sinergasilus polycolpus in farmed silver and bighead carp in a reservoir
}

\author{
Gui T. Wang ${ }^{1, *}$, Wen X. Li ${ }^{1}$, Wei J. Yao ${ }^{1}$, P. Nie ${ }^{1,2}$ \\ ${ }^{1}$ Laboratory of Fish Diseases, Institute of Hydrobiology, Chinese Academy of Sciences, Wuhan 430072, Hubei Province, PR China \\ ${ }^{2}$ State Key Laboratory of Freshwater Ecology and Biotechnology, Institute of Hydrobiology, Chinese Academy of Sciences, \\ Wuhan 430072, Hubei Province, PR China
}

\begin{abstract}
The frequency distributions of the parasitic copepod Sinergasilus polycolpus were examined in silver carp Hypophthalmichthys molitrix and bighead carp Aristichthys nobilis during a disease outbreak of the 2 species of fish in a reservoir in China. The mean abundance of the copepod was positively related with host length and age, and the overdispersion of the copepod in both silver and bighead carp was fitted well with negative binomial distribution. Although parasite-induced host mortality was observed, a peaked ageparasite abundance curve was not detected in the present parasite-host system. It is also proposed that this peaked ageabundance curve is unlikely to be observed in its natural host populations.
\end{abstract}

KEY WORDS: Frequency distribution - Parasitic copepod . Sinergasilus polycolpus $\cdot$ Mortality $\cdot$ Silver carp $\cdot$ Hypophthalmichthys molitrix $\cdot$ Bighead carp $\cdot$ Aristichthys nobilis

Resale or republication not permitted without written consent of the publisher

In China, the silver carp Hypophthalmichthys molitrix (Valenciennes) and bighead carp Aristichthys nobilis (Richardson) are among the most important farmed fish, i.e. the so-called 'four major fish species', in ponds, as well as in lakes and reservoirs. Their culture is often, and in some circumstances seriously, influenced by diseases (Yin \& Xu 1995, Zhang et al. 1999). Although bacteria are the most common causes of diseases (Yin \& Xu 1995), several species of parasites have been reported as important pathogens, among which Sinergasilus polycolpus, a specific parasitic copepod found on these 2 species of fish, is the most important (Zhang et al. 1999, Nie \& Yao 2000). However, the available literature on $S$. polycolpus is only related to its general description and seasonality

*E-mail: gtwang@ihb.ac.cn
(Kuang \& Qian 1991, Nie \& Yao 2000). The present study examines the frequency distribution of the copepod in silver and bighead carp during a disease outbreak in a reservoir in Sichuan province of China.

The Xingfu reservoir is located near the city of Neijiang in Sichuan province; the reservoir has an area of about $0.2 \mathrm{~km}^{2}$ and average water depth is $4 \mathrm{~m}$. It has been used for stocking fishery. Beginning in early August 2000, mortalities of silver and bighead carp occurred and Sinergasilus polycolpus was identified as the pathogen. From 22 to 24 August, 326 silver carp and 68 bighead carp were netted in order to examine the copepod. The fork length of each fish was measured, and several scales between the dorsal fin and lateral line were removed. The gills were dissected, examined and the number of copepods on each fish was recorded. The scales were cleaned in water and pressed between 2 pieces of glass before being examined under a microscope for the determination of age in accordance with the methods described by Wang et al. (1960). The significance of correlations between the number of copepods on each fish and the fish length and age was analyzed for the 2 species of fish by using the correlation matrices on the computer program STATISTICA. The differences in the mean abundance of different fish length and age groups were compared using a 2-sample $t$-test.

In the present investigation, silver and bighead carp infected with the copepod Sinergasilus polycolpus showed evidently pathologic changes. The major symptoms involved fish whirling and hectic swimming in the upper layer of the water, etc. On the surface of the gills, particularly on the areas around the parasites, mucus had increased markedly. Excess mucus on the gills caused distinct breathing obstruction and even death of the fish. 

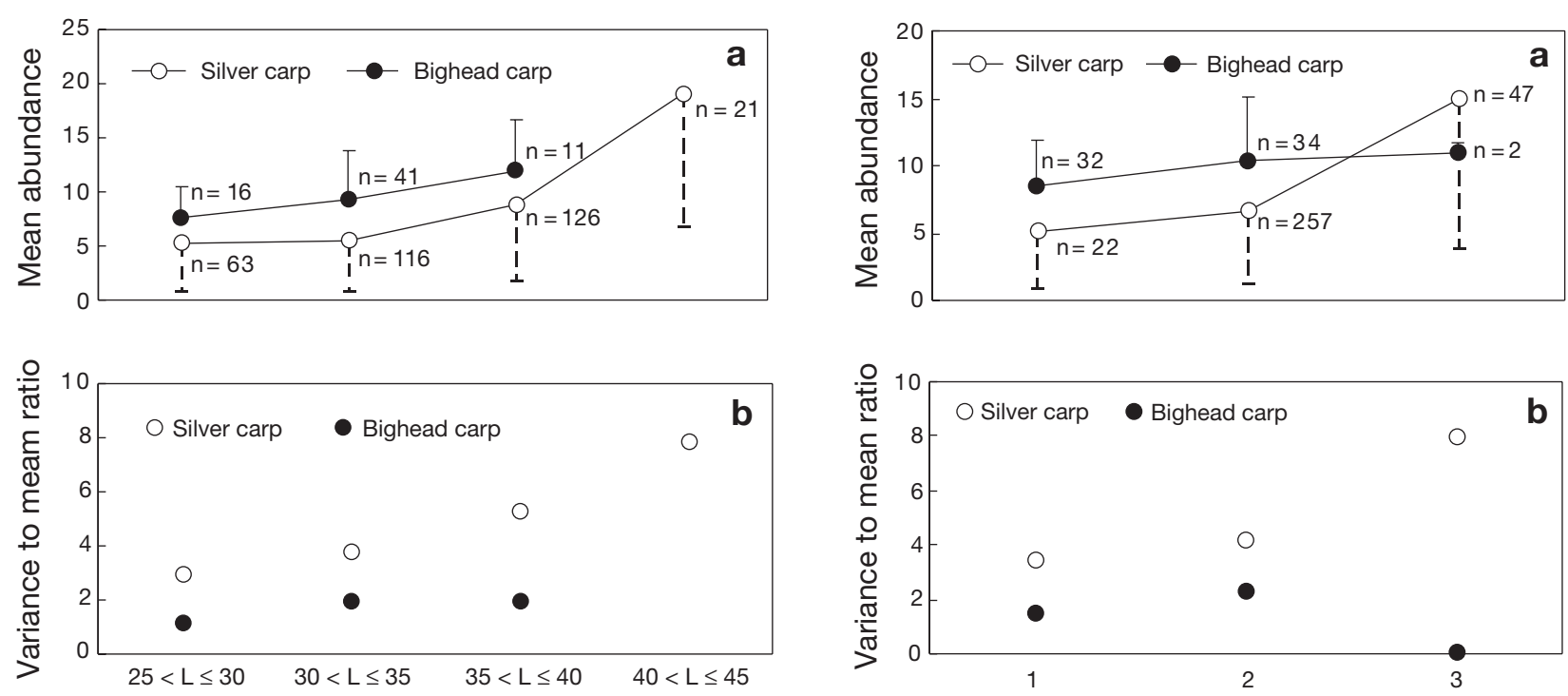

Fish length

Fig. 1. Changes in the (a) mean abundance and (b) variance to mean ratios of the copepod Sinergasilus polycolpus on the silver carp Hypophthalmichthys molitrix and bighead carp Aristichthys nobilis with host fork length. Bars indicate standard deviations

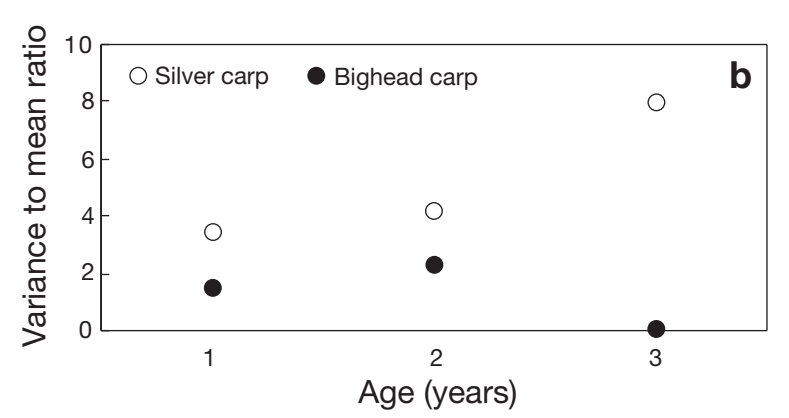

Fig. 2. Changes in the (a) mean abundance and (b) variance to mean ratios of the copepod Sinergasilus polycolpus on the silver carp Hypophthalmichthys molitrix and bighead carp Aristichthys nobilis with host age. Bars indicate standard deviations
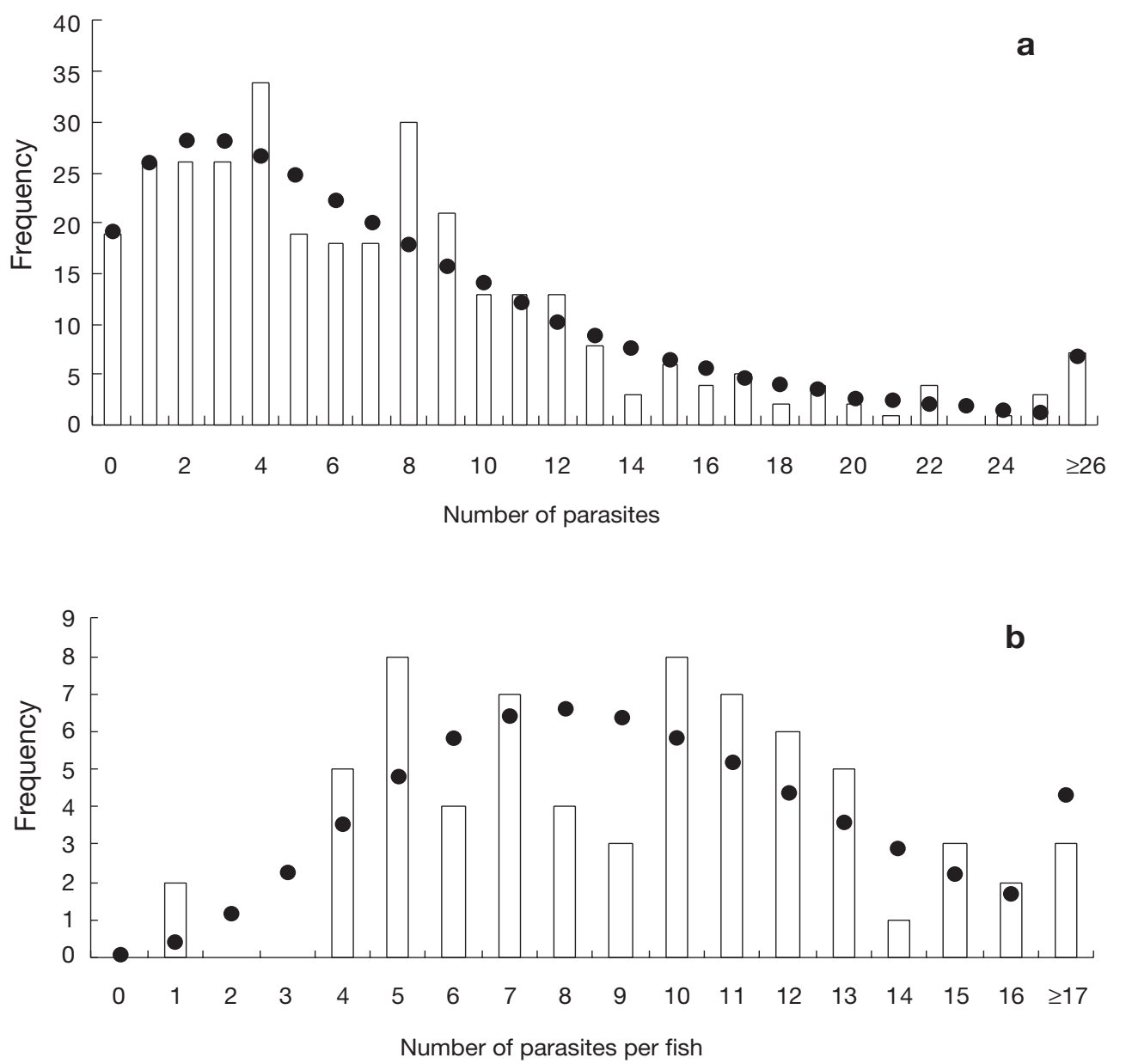

Fig. 3. Frequency distribution of Sinergasilus polycolpus on gills of (a) silver carp Hypophthalmichthys molitrix and (b) bighead carp Aristichthys nobilis. Open bars represent observed frequency and solid circles expected frequency 
The prevalence of Sinergasilus polycolpus on silver and bighead carp was 94.1 and $100 \%$, respectively, and the mean abundance $7.6 \pm 7.0$ (mean \pm SD) and $9.4 \pm 4.3$. The prevalence levels were high for all length groups, being above $90 \%$ for all length groups of silver carp and $100 \%$ for all length groups of bighead carp. The number of copepods on each individual fish was significantly correlated with fish length $\left(\mathrm{r}_{x, y}=\right.$ 0.3807, $\mathrm{p}<0.001$ for silver carp, and $\mathrm{r}_{x, y}=0.2771, \mathrm{p}<$ 0.05 for bighead carp). Higher values of mean abundance were observed in the larger length groups for the 2 species of fish (Fig. 1). Similarly, a significant positive relationship was found between fish age and the number of copepods per fish $\left(\mathrm{r}_{X_{1}, y}=0.3896, \mathrm{p}<0.001\right.$ for silver carp, and $r_{x, y}=0.2681, p<0.05$ for bighead carp). Older age groups had a higher level of mean abundance in both silver and bighead carp (Fig. 2).

The variance to mean ratio for different length and age groups of the 2 fish species was greater than 1, with only 1 exception in the age 3 group of bighead carp (the ratio equals 0.04 ) in which only 2 fish were included (Figs. 1b \& 2b). The ratios were higher in larger length groups as well as in older age groups. The frequency distribution of Sinergasilus polycolpus can be fitted well with the negative binomial distribution in silver $\left(k=1.62, x^{2}=27.28<x^{2}{ }_{0.05[24]}=36.42\right)$ and bighead carp $\left(k=9.65, x^{2}=19.50<x^{2}{ }_{0.05[15]}=25.00\right)$ (Fig. 3). However, in silver carp there are more fish infected with a higher number of parasites.

In a study on the seasonal population dynamics of Sinergasilus polycolpus, Nie \& Yao (2000) found that the overdispersion of the copepod on silver and bighead carp also fitted well with negative binomial distribution, with the majority of the fish uninfected. However, in the present study, the majority of the fish were infected and copepod-induced host mortality had occurred, although the negative binomial distribution provided a good fit for the frequency distribution.

Anderson \& Gordon (1982) and Gordon \& Rau (1982) suggested that a peaked age-parasite abundance curve concomitant with a decline in the degree of parasite dispersion in the older age classes of hosts and a decline in the degree of overdispersion can provide evidence of parasite-induced host mortality, and they provided 2 examples from natural fish populations in support of their suggestion. The role of parasites in the regulation of their host populations has attracted increasing interest in ecology (e.g. Kennedy 1984, Johnson 1992, Jaenike et al. 1995, Rousset et al. 1996). Parasite-induced host mortality has been detected in several host-parasite systems, but other factors have also been suggested as possible reasons for the parasite-induced host mortality. Although the mean abundance is length- or age-related, the age composition of the 2 cyprinid fish examined in the present study may not represent the true structure of their natural populations since larger fish have to be harvested annually for sale at the site of the present study. The observed unpeaked age-abundance curve may be to a large extent due to the fact that the examined parasite-host system existed under aquaculture conditions. However, it may also be expected that the infection level of Sinergasilus polycolpus observed in the present study may not exist in the natural populations of its host, as factors such as host density which plays an important role in increasing parasite transmission rate and in turn the parasite population size in an aquaculture system are unlikely to have the same effect in nature. Thus, $S$. polycolpus-induced host mortality is unlikely to occur in nature. Even in higher density culture conditions such as in pond culture, the infection level of $S$. polycolpus may be very low, as reported by Nie \& Yao (2000). It is therefore of significance for further research to examine epizootiological factors which influence the population dynamics of $S$. polycolpus.

Acknowledgements. This research was financially supported by the Bureau of Life Sciences and Biotechnology, Chinese Academy of Sciences and the National Natural Science Foundation of China, projects 1999051 and 30025035, respectively. Our thanks are also due to Mr. Z. H. Duan, S. G. Dan and J. Sun for their assistance in the determination of fish age.

\section{LITERATURE CITED}

Anderson RM, Gordon DM (1982) Processes influencing the distribution of parasite numbers within host populations with special emphasis on parasite-induced host mortalities. Parasitology 85:373-398

Gordon DM, Rau ME (1982) Possible evidence for mortality induced by the parasite Apatemon gracilis in a population of brook sticklebacks (Culaea inconstans). Parasitology 84: 41-47

Jaenike J, Benway H, Stevens G (1995) Parasite-induced mortality in mycophagous Drosophila. Ecology 76:383-391

Johnson SG (1992) Parasite-induced parthenogenesis in a freshwater snail: stable, persistent patterns of parasitism. Oecologia 89:533-541

Kennedy CR (1984) The frequency distributions in an attempt to detect host mortality induced by infections of diplostomatid metacercariae. Parasitology 89:209-220

Kuang P, Qian J (1991) Economic fauna of China: parasitic Crustacea of freshwater fishes. Science Press, Beijing (in Chinese)

Nie P, Yao WJ (2000) Seasonal population dynamics of parasitic copepods, Sinergasilus spp. on farmed fish in China. Aquaculture 187:239-245

Rousset F, Thomas F, De Meeûs T, Renaud F (1996) Inference of parasite-induced host mortality from distribution of parasite loads. Ecology 77:2203-2211

Wang Y, Qi A, Dai R, Lu B, Xu B (1960) Determination of the age of Hypophthalmichthys molitrix and Aristichthys nobilis Scientia 4:120-121 (in Chinese)

Yin Z, Xu B (1995) Studies on the bacteriosis of fishes. Acta Hydrobiol. Sin 19:76-83 (in Chinese with English abstract)

Zhang J, Qiu Z, Ding X (1999) Parasites and parasitic diseases of fishes. Science Press, Beijing (in Chinese) 